\title{
Films: The Space to Propagate Gender Equity
}

\section{Jereena Babu}

\author{
Department of English Studies, Christ (Deemed to be) University, Bangalore, India
}

Received: 13 Nov 2020; Received in revised form: 12 Dec 2020; Accepted: 21 Dec 2020; Available online: 27 Dec 2020 (C)2020 The Author(s). Published by Infogain Publication. This is an open access article under the CC BY license (https://creativecommons.org/licenses/by/4.0/).

\begin{abstract}
Gender when portrayed in films has not always shown justice to all genders. Many show women as vulnerable, who need a savior to pull them out of whatever neck-deep situation they are stuck in. Men have always had the upper, masculine side, having to face all the tough situations, take bullets for their women or family, and maybe even sacrifice his life for the greater good. The other variants which have been repressed for so long are only still gaining their spotlight in film and society. The role that film and media play in the life of a young adult paves a huge way into their thoughts of reconsidering their preferred role models and thinking pattern when it comes to giving equal on-screen time, opportunity and portraying gender equity in the film industry. Gender should not be treated as a social construct rather it should be valued based on individual preferences of representing themselves to society. Films should by all means be able to present gender equity to the public because what else can catch the attention of the public if not higher quality definition moving pictures on a monumental screen?
\end{abstract}

My paper will focus on the importance of constructing gender through the right lens, how it paves its way to the minds of today's generation and on the significance of equity of genders in the film industry.

Keywords- gender equity, social construct.

Gender equality is a human fight. Even though this is a very common statement it is sadly nothing but the truth. While a lot of people argue on equal rights for women and other strata of gender in reality, the media is inattentive to these protests as they produce movies of their own kind not considering the viewpoints of the people who represent their main source of income. Until recent years, this struggle to be represented and treated equally in the film industry was mainly a women's fight but as of now, the space has been expanded to many others as well. It is not just about getting equal screen time but it is also largely about how a person is represented in that regard. And though the answer is obvious, we cannot refrain from pointing out the objectification of women and the male chauvinism in the film industry.

The bigger question is, why should gender be portrayed equally? At the end of the day do people really care about this as long as they get to see the movie and enjoy watching their favorite characters on screen? Even though in recent years gender is a term that is trying to break out of its definition, we cannot help but talk about a few things that have been disturbing our generation. Gender cannot be simply categorized into male and female but for the purpose of this paper to be fulfilled this must be carried out. Sexism in the film industry has to banned now more than ever because things won't end up well for the film industry with the rising concerns of women and feminist leaders. Several women working under male directors and producers have found the courage to step up and voice out their opinions on the harassment they face and the way their skills and talent are being looked down at because of the predetermined notion of men always being smarter and more talented than women. If this notion of the "alphamale" keeps up for longer, the retaliation is going to be huge and then these film industries might have to sit back in their recliner chairs for the rest of their lives.

We are adult enough to understand what is morally and ethically right in our generation but what happens to our kids who are growing up in such an environment where all around them they acquire the wrong notions on gender? Guess who gives them the idea of what they are supposed to be at a very young age. Media it is. The films they watch, the animations, the t.v serials all play a vital role in the child's development and understanding of gender at such a young age. If you have noticed, all the male superheroes that the kids adore are so strong and 
masculine and most importantly have super powers that make them so cool. While on the other hand, all the female characters are seen as weak and vulnerable, constantly crying out for help with zero superpowers. All that is important for them is that the female characters are dolled up and that their dressing is attractive enough to draw the attention of the male lead. This is what leads the young girl child to think that her appearance is what matters the most to her. The way she stands, eats, walks, and dresses is what makes her who she is and apparently, that is her only job too. Let the men do what they do always, save the day and earn the credit and the woman at the end of the day and this is what the young boy is bred to believe. As a child, I recall watching some Barbie movies and thinking like every other girl that girls were always meant to wear pretty pink floral clothes and makeup all the time so that a prince would magically appear and take me away. It was already pre-decided in my mind that girls could not ride horses or fight evil monsters as we do not know how to yield a weapon which is again a training only given to boys. But even if some of the Barbie movies showed me that side of girls, some others showed us that girls can be whoever they want and can wear whatever they want to and for them to feel like anything is possible, they just had to believe in themselves and fight for it. This thought of being obsessed over the body and thinking that they have to be presentable all the time is something that has to be wiped out of the minds of young kids. As for boys, the famous statement that "men don't cry" is the worst thing that can be taught to them. The constant reminder from their favorite tv characters that they are born to be strong and courageous and dominant is what sticks to their minds at such a young age. The obsession with wanting to look tall and bulky with tons of muscles and veins popping out of the body, being able to knock people out with a punch, using cool weapons and mastering the art of shooting, fighting like WWE wrestlers, and learning to drive cars in both video games and in the real-life are what inspires them to adopt the male chauvinist attitude at a tender age. How the movies portray girls are how they treat them in real life too. Women embodying gender norms have been so institutionalized in society that it is only appropriate that women cover their bodies using a garment when in reality it is the men who have to be taught to restrict their eyes. The problem is that not just are these women expected to dress up in a restrictive way, rather they are also subjected to having an ideal body being a part of the female gender type. The shape of the body, the texture, the smell, the clothes they wear, and the way they carry themselves is what is believed to exhibit their femininity, highlighted the intersectionality that women faced as opposed to what men faced. This practice of embodiment starts at a very young age for women and this is what constructs a very wrong ideal of gender in their minds. Boys and men end up bullying and assaulting girls thinking that they won't fight back since they are considered weak and girls and women actually or most often don't fight back thinking that they are weak and also because fighting back is not exactly or always their forte. This kind of thinking will motivate one and demotivate the other and this where the media should step in and clear the air of misunderstanding. All this can be avoided if such thought-provoking ideas were not portrayed in films and animations which would color the kids' mind and thinking.

Most films always represent men with so much authority and power and women with attractive and well-maintained figures that men are supposed to ogle over. One such example that can be thought of is the movie "Transformers" where Megan Fox is objectified to suit the concept of the male gaze. She is a mechanic who somehow always appears to be wearing short and revealing clothes and maintaining a certain position while fixing a car. The camera shot started at her slender legs and went up to her face which clearly explains the concept of the male gaze that the director was aiming at, that is, the exact way any male would be expected to observe a woman. The less clothing she had on the more the gaze hence more the viewers. What the viewers missed out on were the problems that the actress faced on the set of the movie. She lodged a complaint against the director for multiple cases of sexual harassment in which she was practically forced to wear uncomfortable, short, and revealing clothes for her role. Since she refused to do that any further she was terminated from the contract which in turn tore her public image down to tatters. Similarly, many such women have spoken out against such issues and have been kicked out of the film industry and had to face a downfall in their careers. But this where the "\#MeToo" came in handy for them and they used this opportunity to talk about the injustice that was committed against them. The media industry should know that nobody will stay silent about this anymore and henceforth movies will have to be created with much precaution. As for the males, most of them are portrayed running up and down through various calamities, saving people and maybe through that sacrificing their likes and at the end of it all wearing torn and tattered clothes with blood oozing out of their skin and multiple gunshot wounds but still alive and healthy and also the hero at the end of the day. There is no reason as to why women can't be doing the same things as they are and still get appreciated for it. But somehow it has to be the 
alpha male who can complete tasks with much ease and saves the distressed damsel.

There were a few women directors and producers who produced a few good movies but still in comparison with the number of male directors in the industry the number is hardly noticeable. Movies like "American Psycho" and "Brave" were co-written and directed by women and these movies are among the top best movies directed and produced. So it is not just that only men are qualified to direct and produce good movies, women also have the capability but not many of them step forward with their ideas as the industry is mainly male dominated. What happens when a woman produces a film is what is important in this context. While most movies show women as vulnerable and having to follow a certain set of standards and rules that are most appropriate in contributing to their image as a woman, this film produced by a woman had set different and bold standards. The movie is called "Brave" and revolves around the life of a princess whose father is a hunter, who is well equipped with her bow and arrow and has no regret in using it. Also when approached by suitors she boldly refuses each of them which is otherwise not suitable for a princess to do. Breaking all standards she also stands against her mother's command of wanting her to act more like a lady just because she admires the sport of archery. This woman director has thus made it easier to think of how women should not be confined to what the society wants them to be rather be who or what they want to be and do what they think is good. "Brave" also did not show a male character in lead who had to help her out thus making it a movie where women were shown as equally powerful, brave and bold as men are. There is also the pressing issue of pay that is overlooked. Women are paid much less money than men who do the same amount of directing and work. They are also severely under-represented and have less access to resources in the workplace. It was mainly noticed that one in five women were directors or at some high posts in the film industry while the others were not allowed to work under creative positions even though most of them graduated from the same film academy of those men who had got those positions in their place. No one had the courage to speak out against this injustice and hence this issue was left unnoticed.

There's a theory that is associated with women that explains the unconscious desire that a woman has in her mind to be under constant protection or care and through that give up on their own desires and thoughts. This is called the "Cinderella Complex". It revolves around the ideas like those we saw at an earlier age in cartoons where the prince always saved the princess from her distress. But the real reason for this can be due to the fear of being independent. This again brings us back to the question of how this fear was created. As young children, we are easily influenced by cartoons and movies and this is probably a stepping stone into the world of our thoughts and of how we perceive ourselves to be as shown through the camera's lens. This thought also came about as a process of describing how the princess or in our case a woman had to be; innocent, beautiful and very dependent on whoever was supposed to save her. The very notion of fulfilling all these criteria probably put the woman under so much pressure which resulted in the formation of this complex which she thought to be her only escape. The twisted notion that a woman's life will be only be complete if she gets into a relationship with a man is quite the irony in today's situation as we see more of the woman becoming a slave to men's standardized notions.This complex is what the film industry has utilized for their movies and it is very evident in the movies produced over the years especially with the animation movies.

The measures to make sure that the film industry will refrain from not showcasing gender equity have already been taken by a few countries as per UNESCO's report. Film industry is certainly one of the most creative and powerful mediums and therefore their role as influencers should be considered with utmost certainty and caution as they practically reflect and shape a society's cultures and values. Secretariat of Audiovisual Activities of the Ministry of Culture and the Secretariat of Women's Policies of the Presidency of the Republic of Brazil launched an award which aims at giving increased visibility to the cinematographic work of women's directors and technicians, in order to promote equal opportunities among men and women in the Brazilian audiovisual sector. They also have the thought of extending the program to indigenous women, AfroBrazilian women and women in vulnerable groups. The Swedish Film Industry (SFI) made an agreement which required production funding to be given to directors, producers, scriptwriters to be distributed equally between men and women equally. With the introduction of these measures women in Sweden are finding it much easier to express their thoughts and ideas in the film industry. UNESCO is currently undertaking measures to bring out such initiatives in other countries as well which will make it easier for women to get into the film industry with much ease.

So far this paper talked about how women had difficulty catching up to men in the film industry but there are other strata of gender that should be looked into in the same way. It is not until recently, that the LGBTQ community is 
being portrayed and given value to. Film industry did not consider showing LGBTQ on screen to its viewers in the fear that such movies would not be very much appreciated by the audience. But it is exactly what the audience wants to see so that they get a reassurance that their voices are also being heard and it is not just the filmmakers who take all the decisions. It wasn't easy to bring out the first homosexual film in the 80's in America. The very first film that came close to showing homosexuality was called "The Dickson Experimental Sound Film" though this was not considered queer or flamboyant but rather merely termed fanciful. Although in the years after that, homosexuality was never really considered worth portraying in films until the Great Depression period. During this period, the filmmakers noticed that the number of people turning in to watch movies were dropping significantly and they were almost going through a loss. They decided therefore that introducing queer characters would help rope in the audience again as this was something out of the ordinary for everyone. Hence measures were taken to train actors and actresses into cross-dressers, pansies (the then term used for gay men) and lesbians which would ensure the shock-value to get people back into theaters to watch movies that were "different". Controversial topics such as prostitution and violence were other similar areas where the audience's attention could be captured. Using homosexual representation in these movies hence degraded the status of those who were actually homosexual or queer as they were portrayed as silly and dressing up just for laughs and the movies made sure that the message of why homosexuality cannot be considered had gotten across to every citizen, indicating that involvement in such heinous activities would only make the people mock you and that society would never accept such people. It is around the same time that the supreme court of America decided to pass a law stating that the film industry could not portray such "evil" on screen as they were the leading industry with the power to influence the lot as was the concern of the church. So the film industry had already sketched a portrait of what homosexuality was through the films and it is to break those standardized notions of the people that they should be essentially working for. There are many movies now that illustrate the life of homosexuals the way it actually is and this is what will ultimately be the story that had to be told.

\section{CONCLUSION}

Our understanding of the film industry is very much limited to the number of movies we watch.
We can't possibly and we shouldn't make a conclusion based on our experience of watching one or two films that represent a gender or a community. More importantly it is necessary for the film industry to understand what it means to depict gender equity in their films. In recent years the depiction is getting much better and things are finally falling into place for both the filmmakers and the audience. If this continues successfully, both parties can have a peaceful negotiation and move forward without any difficulty. Even though most film industries are profit driven, one mustn't make movies for the sole intention of profit and be cynical in their approach towards men, women and the other sections of society. The most important message we can convey to the film industry is to go with the choice that scares them the most because that is the decision that will help them to grow and as long as they know that it is good enough to make people stand on their feet and applaud for the right cause.

\section{REFERENCES}

[1] Frackman, Kyle, and Faye Stewart. Gender and Sexuality in East German Film: Intimacy and Alienation. Boydell and Brewer, 2018, pp 42- 61. JSTOR

[2] Fridley, Brianna. "The Male Gaze in Transformers" Femfilm18, femfilm18.wordpress.com

[3] Shohat, Ella. "In On the Arab-Jew, Palestine, and Other Displacements: Selected Writings of Ella Shohat." Gender in Hollywood's Orient, 2017, 238-44, pp 238- 244. JSTOR

[4] Stojanova, Christina, and Dana Duma. The New Romanian Cinema. Edinburgh University Press, 2019, pp 167-179. JSTOR 